\title{
Julián David Romero Torres. "A la lucha he venido". La campaña electoral de 1930 en Colombia. Bogotá: Universidad del Rosario, 2018.
}

http://dx.doi.org/10.15648/hc.36.2020.13

La investigación de Julián se ocupa de una campaña electoral de mucha relevancia para la historia política de la primera mitad del siglo XX: la que puso fin al periodo conocido como la hegemonía conservadora en 1930. La vertiginosa campaña presidencial del liberal Enrique Olaya Herrera duró aproximadamente tres semanas, pero la consolidación de las candidaturas conservadoras de Guillermo Valencia y Alfredo Vásquez Cobo se dio a mediados de 1929. Es en este punto que el autor inicia el estudio de la campaña, partiendo del análisis de la difícil situación del conservatismo durante los meses finales de la administración de Miguel Abadía Méndez, dificultades que superaban la conocida indecisión de monseñor Ismael Perdomo para otorgar su bendición a una de las candidaturas conservadoras.

Colombia es un país de elecciones. Esta sentencia aparece con mucha frecuencia tanto en notas de prensa como en las investigaciones de la historia política republicana. Otra idea que circula constantemente es que las elecciones en Colombia han estado y siguen estando dominadas por la violencia, el fraude, el constreñimiento al elector y otras prácticas que deslegitiman la democracia. En ese sentido, las jornadas electorales tendrían como finalidad principal mantener a la élite dirigente en el disfrute del poder político. A pesar de que estas observaciones se repiten continuamente en la historiografía colombiana, una revisión de esta demuestra que son escasos los estudios que tienen como objeto la historia de las elecciones y de sus instituciones, así como de los actores y prácticas involucrados en las contiendas electorales. No obstante, en 
los últimos años el análisis histórico de las elecciones en Colombia ha cobrado alguna relevancia. El interés de los historiadores - colombianos y extranjeros - está conectado con el tardío despertar de la historia política a finales del siglo XX: "lo político" se entendió entonces como algo más complejo, más profundo y más relevante históricamente que la concepción tradicional de "la política". El trabajo de Julián David Romero Torres pretende continuar esa tradición en construcción en su objetivo de pensar lo electoral a partir de categorías que superan los marcos tradicionales de la ciencia política, estos más preocupados por la política como estadística y no por lo político como proceso.

Para el autor, el problema no radica necesariamente en una carencia de las investigaciones sobre la cuestión electoral, toda vez que el desinterés de la historiografía es más notorio en el estudio de las campañas, ya que la mirada de los investigadores se ha concentrado en el resultado de los escrutinios, los cuales, según él, han despertado mayor interés que las actividades relacionadas al proselitismo y movilización del voto. Para el autor, así como para historiadores como Medófilo Medina y César Ayala, principales referentes historiográficos del autor, las campañas afloran en la historiografía política no solo para dar cuenta de la sucesión presidencial y de los principales cargos de representación, sino que son fundamentales para develar la urdimbre de la política colombiana. Las campañas han desempeñado un papel fundamental para el conjunto de la sociedad: si se entienden no solo como un medio sino como un fin en sí mismas, revelan todas las estrategias que han utilizado las élites políticas para permanecer en el poder; para Romero, las campañas electorales deben ser observadas desde su teatralidad, ya que se constituyen principalmente en un performance dominado por las emociones.

El libro está organizado en cuatro capítulos, además de las respectivas introducción y conclusiones. En el primer capítulo, el autor aborda diversas temáticas que se considera que el lector debe conocer para contextualizar la campaña presidencial de 1930: primero, una caracterización de los principales periódicos de la época, acompañada de un análisis de cómo los medios de comunicación impresos se constituyeron en el principal escenario en el que se desarrollaba la campaña; en segundo lugar, una alusión historiográfica que aunque detecta los vacíos 
en cuanto al estudio de las campañas electorales - lo que contrastaría con la frecuencia de la actividad electoral en la historia colombiana-, no entabla un diálogo con trabajos recientes sobre la democracia colombiana que, sin duda, aportarían considerablemente al planteamiento general de la obra; ${ }^{1}$ y en tercer lugar, una referencia a las orientaciones historiográficas y teóricas del libro, y que se conectan con una percepción de la política fundamentalmente desde su esfera simbólica y teatral. Este enfoque ya ha sido utilizado para abordar el estudio de la cuestión electoral, incluso del periodo estudiado por Romero ${ }^{2}$.

El autor plantea en un principio que espera desarrollar "un esbozo de una posible teoría sobre la campaña electoral". Sin embargo, desde el segundo capítulo, el libro es primordialmente una entretenida narración en la que el autor entreteje el tejemaneje de la configuración del panorama electoral y de la indefinición de la candidatura conservadora; en un tercer capítulo, de apenas unas pocas páginas, se comentan las dificultades que enfrentó la candidatura de Alberto Castrillón del Partido Socialista Revolucionario, las que se reflejan en la poca información que el autor pudo hallar sobre la actividad proselitista del candidato socialista; finalmente, en el cuarto capítulo se presenta la construcción de la candidatura mesiánica del moderado Olaya, precedida de convenientes vacilaciones para luego dar paso a una vertiginosa actividad política en diferentes escenarios que desencadenaron en su triunfo.

El texto renuncia hasta cierto punto a las convenciones de los textos académicos, razón por la cual hay pocos llamados de notas al pie y solo con las referencias a fuentes primarias y secundarias que el autor con-

1 Estos son algunos de los trabajos más recientes que no aparecen referenciados en la obra: Francisco Gutiérrez Sanín, El orangután con sacoleva. Cien años de democracia y represión en Colombia (1910-2010) (Bogotá: Iepri, Debate, 2010); Isidro Vanegas Useche, Todas son iguales. Estudios sobre la democracia en Colombia. (Bogotá: Universidad Externado de Colombia, 2010); Fernando Mayorga García, Historia de la organización electoral en Colombia (1888-2012): vicisitudes de la consolidación democrática en un país complejo (Bogotá: Editorial Universidad del Rosario, 2013); Francisco Gutiérrez Sanín, La destrucción de una República. (Bogotá: Universidad Externado de Colombia, Taurus, 2017); Darío Acevedo Carmona, Ciudadanía, pueblo y plaza pública. Campañas presidenciales en Colombia, 1910-1949 (Medellín: Universidad Nacional de Colombia, 2017).

2 Sonia Milena Jaimes Peñaloza, Teatrocracia y legislación electoral colombiana 1886-1938. Un estudio sobre cultura política y democracia (Bogotá: Universidad del Rosario, 2012). 
sideró más relevantes. Un examen de las mismas nos permite observar que la investigación privilegia la prensa como su principal fuente de información; las ediciones de periódicos como El Tiempo, El Debate y El Nuevo Tiempo, le permitieron al autor acercarse a la dinámica de la campaña: de un lado, las noticias registraban las correrías de los candidatos y los novedosos medios de transporte de que hacían uso, sus intervenciones en plaza pública, las recepciones y festejos privados, así como las diversas manifestaciones de adhesión que recibían en las regiones que visitaban. Con base en esa información, el autor elaboró unos mapas que pretender hacer visible los momentos y los tiempos de la campaña, y a partir de los cuales se puede reafirmar la idea que se tiene de que es en la región Andina y en las principales ciudades de la Costa donde se despliegan históricamente las principales actividades de proselitismo electoral en el país. Por otro lado, en los editoriales, las columnas de opinión y las caricaturas se desarrollaba la definición ideológica de la campaña, la construcción del otro, del rival, que en el caso de los conservadores resultaba ser su copartidario. Este énfasis metodológico llevó al autor a desconocer otro tipo de fuentes que hubieran ampliado y complejizado su objeto de estudio; además, esa carencia podría llevar al lector a plantearse una pregunta: ¿el libro es un estudio de la campaña presidencial de Colombia en 1930 o un análisis de la forma en que esta fue registrada por la prensa?

Desde la elección de la imagen de la carátula (una caricatura elaborada por Rendón de Carlos E. Restrepo), se sobreentiende que la obra de Romero abordaría la cuestión del republicanismo. La Unión Republicana, como proyecto político de los sectores moderados de los partidos liberal y conservador, y la que generalmente se ha planteado como una iniciativa frustrada, fue la fuerza que direccionó en gran medida los cambios por los que atravesó la democracia colombiana a partir de 1910. El peligro que representaban el caudillismo, el militarismo y la exacerbación de los odios partidistas impulsó a líderes de los dos partidos como Carlos E. Restrepo, Eduardo Santos, Nicolás Esguerra y el mismo Olaya, entre otros, a promover reformas electorales para ampliar controladamente el derecho al sufragio y garantizar la participación de los liberales en las elecciones. Todos estos vínculos se activan a finales de los años veinte, cuando la debilidad del gobierno conservador se tra- 
dujo en represión política y social, y en dos candidaturas que parecían revivir los temores de los republicanos. En el libro solo se da cuenta de la última parte de este proceso, por lo que investigaciones posteriores deben ahondar más en él, recurriendo a otras fuentes de información más allá del tradicional examen de la prensa. Es por esta razón que en libro aparece un tanto desdibujado el importante papel de Restrepo en la consolidación y posterior triunfo de la campaña de Olaya, ya que el primero no es necesariamente el protagonista de la coyuntura diaria de la campaña.

En definitiva, lo que se manifiesta es que para el caso colombiano todavía persiste un gran desconocimiento tanto de la historia de las campañas electorales como del ejercicio del derecho al voto; es en este sentido que resulta importante el aporte que hace el autor con su investigación sobre la campaña presidencial de 1930. Es de esperar entonces que el desarrollo de la historiografía política, enriquecida por la incorporación al análisis histórico de la dimensión cultural de la política, la ampliación de las fuentes de información de las que se valen los historiadores, y la historización de los conceptos asociados a la política, nos conduzca a conjurar el fraccionamiento entre campañas y elecciones, y así concebir lo electoral desde una perspectiva holística.

\section{Adriana Rodríguez Franco}

Universidad del Tolima arodriguezfr@ut.edu.co arodriguezfr@gmail.com 